\title{
Effects of local administration of hydrocortisone on cartilage degradation in vivo
}

\author{
A. D. SEDGWICK, Y. M. SIN, A. R. MOORE, J.C. W. EDW AR DS, AN D \\ D. A. WILLOUGHB Y
}

From the Department of Experimental Pathology, St Bartholomew's Hospital Medical College, West Smithfield, London EC1A $7 B E$

SUMMARY The effect of corticosteroid on autologous minced cartilage transplanted into facsimile synovial cavities has been studied. The soluble form of hydrocortisone, as the sodium succinate, reduced proteoglycan loss from cartilage in a dose-dependent manner. In contrast, insoluble hydrocortisone acetate, if given directly into the cartilage-containing cavity, enhanced proteoglycan loss. Injection of the same dose of drug into the inflamed lining tissue reversed this effect. These findings suggest that intra-articular steroid injection may enhance cartilage damage if insoluble preparations are used, but that this may be overcome by injecting into the inflamed lining tissue rather than into the cavity itself.

Corticosteroids have a potent anti-inflammatory effect on chronic rheumatoid synovitis. Their effects on cartilage, however, remain uncertain and a cause for concern. Certain evidence points to a possible beneficial effect. Hydrocortisone has been shown to inhibit proteoglycan breakdown in cartilage/synovium cocultures in vitro. ${ }^{12}$ The production of mediators of cartilage breakdown, such as catabolin and proteolytic enzymes, can be inhibited by hydrocortisone.$^{34}$ On the other hand Chandler and Wright ${ }^{5}$ showed that, although intra-articular injection of hydrocortisone leads to clinical improvement of synovitis, radiological deterioration (indicating cartilage loss) still occurs. Mankin and Conger ${ }^{6}$ produced further evidence for a deleterious effect of hydrocortisone on cartilage metabolism when injected into normal rabbit knees.

It is clear that the use of injected corticosteroids in chronic synovitis represents a compromise between known benefits and possible hazards. The present study was prompted by two clinical observations, which suggested that more detailed study of the site and dose of injection in an experimental model would be useful. Firstly, it was noted that injection of steroid into synovial tissue rather than the synovial cavity itself was often as effective in abolishing symptoms and swelling, at least in the hand joints. Secondly, it was felt that much of the value of intra-articular

Accepted for publication 31 October 1983.

Correspondence to Dr A. D. Sedgwick. injection often comes from the systemic effect on other joints. This raises the question whether the relatively painful technique of joint injection has much advantage over intermittent intramuscular injection, a method which some rheumatologists have been using with considerable success over many years.

We have recently demonstrated that autologous cartilage implants in facsimile synovial cavities created by air injection ${ }^{7}$ offer a useful method of studying cartilage degradation in vivo. ${ }^{8}$ In the present study we have used this model to compare the effects of various doses of corticosteroid preparations given either into the cavity or into the adjacent lining tissue.

\section{Materials and methods}

Animals. Outbred SAS/4 male mice weighing approximately $35 \mathrm{~g}$ were used throughout. The animals were kept in a temperature controlled environment and fed with food and water ad libitum. Not less than 6 mice were used for each experimental observation.

Air pouch. The air pouch as described by Edwards et $a .^{7}{ }^{7}$ was used as the site of cartilage implantation. Mice were injected with $5 \mathrm{ml}$ of air into the subcutaneous tissue in the back. Subsequently $2.5 \mathrm{ml}$ of air was injected into the same cavity every three days to keep the cavity open. Cartilage was implanted into the pouch six days after the initial induction. 
Irritant. Carrageenan, Viscarin 402 (lot 272500), was kindly provided by Marine Colloids, Springfield, USA. This was dissolved in sterile physiological saline at a concentration of $1 \%$ for injection. The solution was stirred continually at $37^{\circ} \mathrm{C}$ to maintain homogeneity. $1 \mathrm{ml}$ of carrageenan solution containing $100 \mathrm{units} / \mathrm{ml}$ penicillin and $100 \mu \mathrm{g} / \mathrm{ml}$ streptomycin was injected into the air pouch 24 hours before implantation of cartilage.

Cartilage. Autologous xiphisternum was used as a source of cartilage. To obtain this mice were anaesthetised with ether and the area around the xiphisternum was shaved and swabbed with $70 \%$ alcohol. A small piece of abdominal wall overlying the xiphisternum was reflected and light pressure was exerted until the cartilage was revealed. The tissue was removed by cutting at the point where the sternal bone is connected to the cartilage. The area of the abdominal wall was then sutured and the overlying skin closed with Michel clips. The cartilage was prepared for implantation by carefully removing the adipose tissue and bone attached to it and then weighed. The cartilage was cut into pieces approximately $0.15 \mathrm{~cm}$ in diameter in a Petri dish containing medium 199 and penicillin and streptomycin in the same concentrations as above. The fragments of cartilage were then placed in Millipore half chambers. A small incision was made in the preformed air pouch and the chamber inserted. The overlying skin was sutured. Seven days after implantation the cartilage pieces were removed for proteoglycan analysis.

Millipore half chambers. A sterilised Millipore filter (pore size $5 \mu \mathrm{m}$ ) was attached to a Millipore ring (13 mm diameter) with Millipore MF cement. This allowed easy recovery of the cartilage pieces.

Hydrocortisone. Hydrocortisone sodium succinate and hydrocortisone acetate were diluted to appropriate concentrations with medium 199. These drugs were injected either directly into the air pouch or into the air pouch lining tissue at the same time as cartilage implantation. Hydrocortisone was prepared in a volume of $1 \mathrm{ml}$ for direct pouch injection or $0.1 \mathrm{ml}$ for lining tissue injection.

Proteoglycan assay. The amount of proteoglycan in autologous cartilage was determined by the method of Farndale et al. ${ }^{9}$ The cartilage was digested at $65^{\circ} \mathrm{C}$ for one hour with papain (type III sigma) and then reacted with 1,9 , dimethylmethylene blue for spectrophotometry. The amount of proteoglycan loss was calculated by subtracting the mean values of transplants from those of control, and expressed as percentages.

\section{Results}

Table 1 shows the results for experiments in which
Table 1 The effect of hydrocortisone salts on proteoglycan loss from hyaline cartilage fragments transplanted to inflamed air pouches. Change in proteoglycan is expressed as a percentage of normal xiphisternal cartilage

\begin{tabular}{llll}
\hline Treatment & Route & $\begin{array}{c}\text { Dose } \\
(\mathrm{mg})\end{array}$ & $\begin{array}{l}\text { Mean proteoglycan } \\
\text { change \% }\end{array}$ \\
\hline Control & & & $-28 \cdot 8 \pm 5 \cdot 0$ \\
$\begin{array}{l}\text { Hydrocortisone } \\
\text { sodium succinate } \\
\text { (soluble) }\end{array}$ & $\begin{array}{l}\text { Cavity } \\
\text { Cavity }\end{array}$ & 5 & $+11 \cdot 6+1 \cdot 6^{*}$ \\
& Lining & 5 & $-14 \cdot 1 \pm 7 \cdot 5^{* *}$ \\
Lining & 1 & $-5 \cdot 5 \pm 9 \cdot 9^{* *}$ \\
$\begin{array}{l}\text { Hydrocortisone } \\
\text { acetate (insoluble) }\end{array}$ & $\begin{array}{l}\text { Cavity } \\
\text { Cavity }\end{array}$ & 5 & $-48 \cdot 9 \pm 4 \cdot 6^{*}$ \\
& Lining & 5 & $-20 \cdot 0 \pm 11 \cdot 0(\mathrm{NS})$ \\
& Lining & 1 & $-10 \cdot 0 \pm 3 \cdot 0^{* *}$ \\
& & & $-12 \cdot 0 \pm 3 \cdot 0^{* *}$ \\
\hline
\end{tabular}

${ }^{*} p<0.01 .{ }^{* *} p<0 \cdot 02 .{ }^{* * *} p<0 \cdot 001 . \mathrm{NS}=$ not significant, $p>0.05$.

the loss of proteoglycan from cartilage pieces from untreated animals was compared with that from animals treated with soluble hydrocortisone sodium succinate. Values indicate the percentage change from normal xiphisternal cartilage proteoglycan levels. Minced autologous cartilage transplanted into normal animals lost $28.8 \%$ of its proteoglycan. In comparison, cartilage transplanted into hydrocortisone sodium succinate-treated animals showed a decreased loss in proteoglycan. Results are given for drug given either into the cavity or into the lining tissue. Proteoglycan loss was reduced in a dosedependent manner when this form of hydrocortisone was given by either route. Maximum protection was found with $5 \mathrm{mg}$ of hydrocortisone sodium succinate injected directly into the cavity. At this dose no proteoglycan loss was seen. There may even have been an increase in proteoglycan, although the positive figure is not statistically significantly different from no change.

Table 1 also shows the results from experiments where hydrocortisone acetate was used. This agent was found to enhance the loss of proteoglycan from cartilage pieces significantly when administered directly into the pouch at a dose of $5 \mathrm{mg}$. As the concentration of drug was lowered, no enhanced loss of proteoglycan could be detected. When injected into the lining tissue, hydrocortisone acetate reduced proteoglycan loss at both $5 \mathrm{mg}$ and $1 \mathrm{mg}$ doses.

\section{Discussion}

The air pouch has been used for cartilage implantation because it demonstrates many characteristic features of synovium. We have previously shown that the injection of air into the dorsal tissues of rodents 
induces a lining structure coated in macrophages ('synovial type A cells') and pinocytic fibroblastic cells ('synovial type B cells') after six days. ${ }^{7}$ We have also shown that this tissue is highly reactive to inflammatory stimuli in a similar way to synovial tissue, possibly owing to its vascular pattern and its organised lining structure acting as a mechanical barrier to dispersion of irritants and inflammatory mediators. ${ }^{10}$ Injection of carrageenan into the cavity induces an inflammatory reaction, producing an environment similar to that of inflamed synovium. Using this system we have been examining the breakdown of cartilage. ${ }^{\gamma}$ The present study extends this to study the effects of drugs on experimentally induced cartilage breakdown in vivo.

In this model system locally injected hydrocortisone sodium succinate reduces the rate of proteoglycan loss from cartilage when injected either into the cartilage-containing cavity or into the lining tissue. In contrast, insoluble hydrocortisone ace tate at a dose of $5 \mathrm{mg}$ increases the rate of proteoglycan loss when injected directly into the cavity. Nevertheless the same dose, when injected into the lining tissue, was found to reduce proteoglycan loss. This suggests that direct contact between insoluble hydrocortisone acetate and damaged cartilage will produce an adverse effect rather than protection.

The mediation of cartilage degradation in the air pouch, as in the rheumatoid joint, is probably complex. A combination of both infiltrating leucocytes and tissue fixed cells are involved and probably interact. Such cells may secrete both proteolytic enzymes and mediators such as catabolin which act either directly on the cartilage matrix or induce autodegradation by chondrocytes. ${ }^{11}$ Local hydrocortisone injection could reduce cartilage degradation via its action on one or more of these components. Hydrocortisone has been shown to cause a reduction in cell migration after implantation of non-resorbable plastic sponge in rats. ${ }^{12}$ Experiments using human subjects with the skin window technique show that treatment with hydrocortisone was associated with a striking reduction in the number of cells in the exudate. ${ }^{13}$ Thus steroids may be acting by inhibiting cell movement into the area in response to the carrageenan and minced cartilage. Although steroids can affect the inflammatory process, there has been some controversy as to whether they have a beneficial or harmful effect on associated cartilage breakdown. Mankin and Conger ${ }^{6}$ showed that the intraarticular injection of cortisol in normal rabbits decreases glycine ${ }^{3} \mathrm{H}$ incorporation (used as an index of matrix synthesis). The air pouch system has the advantage in allowing the study of the effects of steroids on established degradation. Previous in-vitro work showed that steroids inhibited synovial proteoglycanase levels but did not show a noticeable effect on proteoglycan breakdown. ${ }^{4}$ The present results suggest that proteoglycan breakdown is reduced in vivo.

In conclusion, the present results show that the injection of an insoluble corticosteroid preparation directly into a cartilage-containing cavity can have an adverse effect on cartilage breakdown. This can, however, be prevented by injection of the drug into the nearby inflamed lining tissue. The effects on cartilage are dose-dependent, and further study may help establish a rational optimum dose range.

This work was supported by a commonwealth Academic Fellowship (Dr Sin), and the Arthritis and Rheumatism Council and Knights Bachelor Fund.

\section{References}

1 Steinberg J, Tsukamoto S, Sledge C B. A tissue culture model of cartilage breakdown in rheumatoid arthritis III. Effects of antirheumatic drugs. Arthritis Rheum 1979; 22: 877-85.

2 Panagides J, Landes M J, Sloboda S. Destruction of articular cartilage by arthritic synovium in vitro: mechanism of breakdown and effects of indomethacin and prednisolone. Agents Actions 1980; 10: 22-30.

3 Sheppeard H, Pilsworth L M C, Hazleman B, Dingle J T. Effects of antirheumatoid drugs on production and action of catabolin. Ann Rheum Dis 1981; 40: 202-5.

4 Crossley M J, Hunneyball I M. Biochemical and pharmacological studies on synovium-cartilage interactions in organ culture. Eur J Rheumatol In flamm 1982; 5: 15-29.

5 Chandler G N, Wright V. Deleterious effect of intra-articular hydrocortisone. Lancet 1958; ii: 661-3.

6 Mank in H J, Conger A B. The acute effects of intra-articular hydrocortisone on articular cartilage in rabbits. J Bone Joint Surg 1966; 48A: 1383-8.

7 Edwards J C W, Sedgwick A D, Willoughby D A. The formation of a structure with the features of synovial lining by subcutaneous injection of air: an in vivo tissue culture system. J Pathol 1981; 134: 147-53.

8 Sin Y M, Sedgwick A D, Willoughby D A. Studies on the mechanism of cartilage degradation. J Pathol 1984: 142: 23-30.

9 Farndale R W, Sayers C A, Barrett A J. A direct spectrophotometric microassay for sulphated glycosaminoglycans in cartilage culture. Connect Tissue Res 1982; 9: 247-51.

10 Sedgwick A D, Sin Y M. Edwards J C W, Willoughby D A. Increased inflammatory reactivity in newly formed lining tissue. J Pathol 1983; 141: 483-95.

11 Dingle J T. Catabolin-a cartilage catabolic factor from synovium. Clinical Orthop 1981; 156: 219-31.

12 Saxena P N. Effect of drugs on the early inflammatory reaction. Arch Int Pharmacodyn Ther 1960; 126: 228-92.

13 Boggs D R, Athens J W, Cartwright G E, Wintrobe M M. The effect of adrenal glucocorticosteroids upon the cellular composition of inflammatory exudates. Am J Pathol 1964; 44: 763-81. 